\title{
Acute Facial Dyplegia and Rhabdomyolisis: Case Report and Review of Literature
}

\author{
Maria Sofia Cotelli ${ }^{1}$, Filippo Manelli ${ }^{2}$, Marinella Turla ${ }^{1}$ \\ ${ }^{1}$ Neurology Unit, Azienda Socio Sanitaria Territoriale Valcamonica-Esine, Brescia, Italy \\ ${ }^{2}$ Emergency Unit, Azienda Socio Sanitaria Territoriale Valcamonica-Esine, Brescia, Italy
}

Email address:

cotellim@gmail.com (M. S. Cotelli), filippo.manelli@gmail.com(F. Manelli), marinellaturla@gmail.com (M. Turla)

\section{To cite this article:}

Maria Sofia Cotelli, Filippo Manelli, Marinella Turla. Acute Facial Dyplegia and Rhabdomyolisis: Case Report and Review of Literature. Clinical Medicine Research. Special Issue: Neurology Emergency. Vol. 8, No. 4, 2019, pp. 85-92. doi: 10.11648/j.cmr.20190804.13

Received: August 14, 2019; Accepted: August 26, 2019; Published: September 12, 2019

\begin{abstract}
In 1916, Guillain, Barré and Strohl reported on two cases of acute flaccid paralysis with high cerebrospinal fluid protein levels and normal cell counts-novel findings that identified the disease we now know as Guillain-Barré syndrome (GBS). 100 years on, we have made great progress with the clinical and pathological characterization of GBS. GBS is an acute/subacute-onset polyradiculoneuropathy typically presenting with sensory symptoms and weakness over several days, often leading to quadriparesis. Approximately $70 \%$ of patients report a recent preceding upper or lower respiratory tract infection or gastrointestinal illness. The interplay between the microbial and host factors that dictate whether and how the immune response shifts towards autoreactivity is still unclear, and nothing is known about the genetic and environmental factors that affect an individual's susceptibility to the disease. Facial Diplegia with Paresthesias is a rare localized variant of GBS in which patient presents with simultaneous facial diplegia, distal limb paresthesias and minimal or no motor weakness. Treatment with intravenous immunoglobulin or plasma exchange is the optimal management approach, alongside supportive care. A common misconception is that the Guillain-Barre syndrome has a good prognosis-but up to $20 \%$ of patients remain severely disabled and approximately $5 \%$ die, despite immunotherapy. We report the case of a woman with acute facial dyplegia and rhabdomyolisis improved after immunoglobulin treatment.
\end{abstract}

Keywords: Facial Dyplegia, Hyperckemia, Guillain Barrè Syndrome

\section{Introduction}

We report the case of a 63 years-old young woman who was admitted to the hospital due to persistent diffuse myalgias with myoglobinuria from about three days. About seven days before she come back from a travel to Cambodia, lasted two weeks. Once at home she suffered for about three days from nausea and vomit without fever, for which she taken antiemetics with benefits.

Her medical history was unremarkable, except for previous excision of basocellular carcinoma, and untreated nodular goiter.

Neurological examination was normal, she only referred diffuse painful myalgias. Cranial nerves, reflexes, strength and sensitivity resulted all normal. She performed blood exams which showed raised value of creatine kinase (2387 UI/L normal value 30-135). Renal function resulted normal. Electromyography resulted normal.
The following day she suddenly developed facial dyplegia, with hypophonia, which was evaluated as grade 6 with House and Brackmann Scale. She also started to complain, after three hours, of worsening dysartria and severe dysphagia.

Lumbar puncture wasn't performed, due to the presence of Arnold Chiari malformation at brain computer tomography and magnetic resonance imaging. She was promptly moved to Intensive care Unit (ICU) due to worsening of dyspnea. Intravenous immunoglobulins $0.4 \mathrm{~g} / \mathrm{Kg}$ were promptly administered for five days.

While in ICU her Creatine kinase values promptly improved and after two days resulted normal.

Electromyography and electroneurography, showed demyelinating type of facial palsy and involvement of upper arms nerves. Chest X-Ray, abdomen and ultrasound resulted negative.

Other blood exams, particularly antinuclear antibodies, extractable nuclear antigens antibodies, anti-double strand 
DNA antibody, serum complement fractions, liver function tests, blood cells count, electrophoresis, hepatitis B, C, human immunodeficiency virus, Syphilis, Coxackievirus, Herpesvirus pattern, Borrelia, resulted all negative, except for mild reduction of thyroid-stimulating hormone $(0.181$ $\mathrm{mcUI} / \mathrm{ml}$ normal value $0.350-4.940)$. A diagnosis of subclinical hyperthyroidism was performed by Endocrinologists and thiamazole $5 \mathrm{mg} \mathrm{1/day} \mathrm{was} \mathrm{started.}$

Otorinolaryngologists and logopedists reported oral phase dysphagia and transcutaneous neuromuscular electrical stimulation was performed.

She was moved to Rehabilitation Unit after 15 days from inhospitalization. Right facial weakness slowly improved in about one month, while at left she developed hemifacial spasm for which she was treated with botulinum toxin at lip elevator and zigumaticus maior muscles.

\section{Review of Literature}

\subsection{Guillain Barre' Syndrome (GBS) Definition}

Guillain-Barré syndrome is the most common cause of acute flaccid paralysis in the developed world [1]. GBS and its related variants comprise a group of acute radiculoneuropathies, with an inflammatory or autoimmune pathophysiology [2]. The classical form of GBS is also known as acute inflammatory demyelinating polyradiculoneuropathy (AIDP) and accounts for $90 \%$ of cases seen in the United States and Europe. Acute inflammatory demyelinating polyradiculoneuropathy typically presents with progressive flaccid paralysis that is often ascending and reaches its nadir within 4 weeks. After a plateau phase of variable duration, recovery begins and often results in a significant return of function [1-2].

\subsection{Epidemiology and History}

The earliest description of GBS dates to 19th century regarding an afebrile generalized paralysis by Wardrop and Ollivier in 1834. Other important landmarks are Landry's report in 1859 about an acute, ascending, predominantly motor paralysis with respiratory failure, leading to death and Osler's in 1892 description of a febrile polyneuritis Guillain, Barré, and Strohl in 1916 described a benign polyneuritis with albumino-cytological dissociation in the cerebrospinal fluid (CSF) and the first report regarding pathology of GBS was by Haymaker and Kernohan in 1949 who reported that edema of the nerve roots was an important change in the early stages of the disease [3-6]. Asbury, Arnason and Adams in 1969 established that the essential lesion is due to perivascular mononuclear inflammatory infiltration of the roots and nerves [7].

With the near-eradication of polio, GBS has become the most common cause of acute flaccid paralysis in developed countries. The incidence of GBS is best known for the United States and Europe, with a consistent annual incidence of 0.84 to 1.9 cases $/ 100000$ population [8]. Despite improved recognition and treatment, GBS continues to be a severe disease. One-quarter of patients will require mechanical ventilation for respiratory failure or airway protection and 3$11 \%$ will die of GBS-related complications [9-11]. Although most patients make substantial recoveries, $20 \%$ to $38 \%$ experience residual disability and more than one-third are forced to change their work and social lives [9-12].

In a systematic literature review incidence resulted lower in children at 0.34 to $1.34 / 100,000[8,12]$. In comparison to younger cases, the incidence of GBS increases after age 50 years from $1.7 / 100,000$ to $3.3 / 100,000$ [8, 12].

Half of GBS patients have an antecedent infection, usually less than 4 weeks prior to symptom onset [13]. The most common infections in adults are respiratory (22-53\%) and gastrointestinal (6-26\%). Preceding infections are more common in children $(67-85 \%)$ with a greater percentage of respiratory $(50-70 \%)$ than gastrointestinal $(7-14 \%)[8,13]$. The most commonly recognized pathogens include Campylobacter Jejuni, Cytomegalovirus, Epstein-Barr virus, and Mycoplasma pneumoniae [14]. Most cases of GBS are sporadic, although rare clusters have been reported after bacterial enteritis [15].

The association of GBS with influenza vaccination was first reported in 1976, when the seasonal vaccination campaign was stopped in the United States due to an excess of GBS cases (relative risk [RR]: 7-8) [16]. However, few studies addressing the potential relationship of GBS to influenza vaccination were published between 1976 and 2009. Since the pandemic outbreak of influenza A in 2009, the vaccine $\mathrm{A} / \mathrm{H} 1 \mathrm{~N} 1 / 2009$ were rapidly developed, manufactured and commercialized, and surveillance systems were reinforced, adapted or set up with the aim of identifying as early as possible any incidence excess of GBS, notably in the United States, wherein an increased risk of GBS associated to influenza vaccine was found $[17,18]$. A recent research performed in 2019 concluded that GBS should be considered an infrequent adverse effect of influenza vaccination, which should not negatively influence the vaccination acceptance [19].

It is now clear that GBS is a true syndrome that encompasses several specific disorders, including the demyelinating form, acute inflammatory demyelinating polyneuropathy (AIDP) and axonal forms, acute motor axonal neuropathy (AMAN) and acute motor and sensory axonal neuropathy (AMSAN) [13, 19]. Other clinical presentations include the Miller Fisher syndrome (a triad of ophthalmoplegia, ataxia, and areflexia), pure sensory neuropathy/neuronopathy, pandysautonomia, oropharyngeal variant, and overlap syndromes [13, 19].

\subsection{Variants}

\subsubsection{Acute Inflammatory Demyelinating Polyneuropathy (AIDP)}

Acute inflammatory demyelinating polyneuropathy accounts for the majority (probably $80 \%$ ) of patients [13, 19]. It is the most common form of GBS in the United States and Western Europe [13, 19]. AIDP typically presents with progressive flaccid paralysis that is often ascending and 
reaches its nadir within 4 weeks $[1,19]$. After a plateau phase of variable duration, recovery begins and often results in a significant return of function [1, 19]. Associated clinical features include areflexia, variable sensory loss, albumincytological dissociation in the cerebrospinal fluid, and variable degrees of demyelination on electrophysiologic testing $[1,19]$.

In AIDP, pathological studies reveal patchy multifocal mononuclear cell infiltrates throughout the peripheral nervous system, with the distribution of inflammation often corresponding to the pattern of clinical deficit [20]. Activated macrophages invade intact myelin sheaths resulting in myelin damage and demyelination [20].

Alternative hypotheses focus on the importance of activated helper (CD4) $\mathrm{T}$ cells, which should react against specific antigens on the surface of Schwann cells or the myelin sheath thereby directing activated macrophages to this region, or on humoral immunity, expecially at early stages of disease [20].

\subsubsection{Acute Inflammatory Demyelinating Polyneuropathy ( $A M A N)$}

Acute motor axonal neuropathy (AMAN) is the most common GBS variant, accounting for as many as $5-10 \%$ of cases in the Western world, with much higher incidence in Asia, particularly for childhood onset GBS, where rates approach $50 \%$ [21].

AMAN is generally characterized by rapidly progressive symmetrical weakness and ensuing respiratory failure [22]. Patients typically have high titers of antibodies to gangliosides (ie, GM1, GD1a, GD1b). Inflammation of the spinal anterior roots may lead to disruption of the blood-CNS barrier [23]. Biopsies show Wallerian-like degeneration without significant lymphocytic inflammation. Prognosis is often quite favorable. Although recovery for many is rapid, severely disabled patients with AMAN may show improvement over a period of years [22, 23].

Nearly $70-75 \%$ of patients with AMAN are seropositive for Campylobacter, with the majority of cases of AMAN being associated with preceding $C$ Jejuni diarrhea. Studies of AMAN post C. Jejuni infection have provided strong support for the concept of molecular mimicry in the pathophysiology of immune neuropathy [21,23]: epidemiological association between GBS and C. jejuni infection, identification of antibodies directed against host antigens (gangliosides) in affected patients, identification of microbial mimics of the target antigen (lipo-oligosaccharides extracted from C. jejuni were found to be identical to GM1 ganglioside), and experimental development of neuropathy in an animal model $[24,25]$.

\subsubsection{Acute Motor-Sensory Axonal Neuropathy (AMSAN)}

Acute motor-sensory axonal neuropathy is similar to AMAN, but with concurrent involvement of the sensory axons, and has a pathomechanism similar to that of AMAN, including frequent antibodies against GM1 and GD1a gangliosides following $\mathrm{C}$. jejuni infection. It often carries a much worse prognosis but the reason of different prognosis is unknown $[13,24]$.

\subsubsection{Miller-Fisher Syndrome}

The second most common GBS variant is the Miller-Fisher syndrome (MFS), characterized by a triad of ophthalmoplegia, areflexia and ataxia. MFS accounts for up to $5 \%$ of GBS cases in the Western world, with rates as high as $25 \%$ in Japan and other Asian countries [25]. This syndrome has been strongly linked to serum anti-GQ1b antibodies in up to $85 \%$ of cases, and less frequently to the closely related ganglioside GT1a, though there is strong cross-reactivity between these two antibodies [26, 27]. There is even greater specificity for the presence of anti-GQ1b antibodies in CSF [28]. This antibody reacts with paranodal myelin epitopes strongly expressed in oculomotor nerves, dorsal root ganglia and muscle spindles, and cerebellar molecular layer, a distribution that fits well with cardinal clinical manifestations [29]. Incomplete forms with acute ophthalmoparesis without ataxia or acute ataxic neuropathy without ophthalmoplegia have also been described [21, 29]. There may also be overlap between subtypes. Patients with MFS or Bickerstaff's brainstem encephalitis who develop limb weakness can be diagnosed as having overlap with GBS. Patients with prominent ophthalmoplegia or ataxia must have overlap with MFS [30].

\subsubsection{Pharyngeal-Cervical-Brachial (PCB)}

Pharyngeal-cervical-brachial variant of Guillain-Barré syndrome is defined by rapidly progressive oropharyngeal and cervicobrachial weakness associated with areflexia in the upper limbs [31]. Serial nerve conduction studies suggest that PCB represents a localised subtype of Guillain-Barré syndrome characterised by axonal rather than demyelinating neuropathy [31]. Power in the lower limbs is usually preserved or only mildly affected, indicating that PCB represents a localised subtype of GBS [32]. It presents with neck, arm, and oropharyngeal weakness, and upper extremity areflexia. Leg strength and reflexes are usually preserved. Findings may be asymmetric [32]. Electrophysiologic features may include mild conduction velocity slowing, low upper extremity CMAP amplitudes, or can be normal [33]. Up to $40 \%$ of patients have anti-GQ1b IgG antibodies [31, 33]. Very often patients presenting with PCB are initially misdiagnosed as having brainstem stroke, myasthenia gravis or botulism, which can often be excluded on clinical history and examination alone $[31,33]$.

Clinical, immunological and neurophysiological studies have shown that PCB forms a continuous spectrum with Miller Fisher syndrome and represents a localised form of axonal GBS [31, 33].

\subsubsection{Pure Sensory Guillain-Barré Syndrome (GBS)}

Sensory Guillain-Barré syndrome (GBS) is an acute demyelinating neuropathy that presents clinically with involvement of the sensory peripheral nerve only. However, the existence of a purely sensory form of GBS remains subject to controversy, since these cases always demonstrate a degree of motor weakness or abnormalities in motor nerve 
conduction studies (NCSs) and are difficult to distinguish from acute sensory neuronopathy [34]. To date, only a few cases of pure sensory GBS have been reported, with the majority of cases being anecdotal and few studies describing a peripheral nerve pathology. Thus, the clinical and pathological features of sensory variant GBS have not been well characterized, and reduced awareness of these features has resulted in delays in the diagnosis and treatment [35].

\subsubsection{Facial Diplegia with Paresthesias (FDP)}

Facial Diplegia with Paresthesias is a rare localized variant of GBS in which patient presents with simultaneous facial diplegia, distal limb paresthesias and minimal or no motor weakness [36, 37]. Deep tendon reflexes are generally absent in FDP variant but rarely can be present or even exaggerated [38]. Diagnosis of GBS is based upon good clinical examination, Cerebrospinal fluid (CSF) analysis and clinical neurophysiological studies. CSF examination done after first week of disease onset often shows albumin cytological dissociation. Nerve conduction studies and Electromyography are very helpful in establishing diagnosis of GBS. NCV studies in FDP often show demyelinating type of neuropathy but axonal polyneuropathy has been also described [39].

\subsubsection{Acute Pandysautonomia}

Acute pandysautonomia presents with orthostatic hypotension, gastroparesis, constipation, diarrhea, ileus, micturition problems, sudomotor/pupillary abnormalities, and neuropathic pain, at times severe, reaching its peak within 1 to 3 weeks [40]. Some, but not all, patients experience sensory loss. Symptoms are mostly due to parasympathetic and cholinergic dysfunction. Half of patients experience significant disability [40].

\subsection{Pathogenesis}

GBS was long considered a homogeneous disorder whose severity was related to the extent of axonal injury arising from demyelinisation; however, it is now known that there are various phenotypes, including acute inflammatory demyelinating polyneuropathy (in which the immune-related injury affects the myelin sheath and related Schwann cells) and acute motor axonal neuropathy, in which the membranes of nerve axons are the primary target [41].

GBS occurs in healthy people, and is not typically associated with an autoimmune or other systemic disorder. It is a mainly humoral mediated rather than T-cell mediated disorder and, in this context, acute motor axonal neuropathy appears as an antibody-mediated attack driven by molecular mimicry between microbial (i.e. glycans) and axolemmal surface molecules (i.e. GM1 and GD1a gangliosides) [42]. On the contrary, the immunological mechanisms involved in acute inflammatory demyelinating polyneuropathy is less clear because of the wide range of immune stimulants that can cause it and the absence of specific antibody biomarkers [43].

Although the distinction between acute motor axonal neuropathy and acute inflammatory demyelinating polyneuropathy seems to be conceptually clear, the margins between the two conditions are not so well defined. Electrophysiological findings are often ambiguous as they indicate acute inflammatory demyelinating polyneuropathy in the early phases and acute motor axonal neuropathy later, or both conditions simultaneously [44].

\subsection{Diagnosis}

\subsubsection{Electrophysiologic Features}

When GBS is suspected, electrophysiologic studies are essential to confirm the diagnosis and exclude its mimics. The finding of multifocal demyelination on early electrodiagnostic testing (or repeated a week later) is extremely helpful in confirming the diagnosis of AIDP with a high sensitivity and specificity. Needle electrode examination is non-specific as it demonstrates reduced recruitment initially and fibrillations potentials three to four weeks after onset [45]. The earliest findings in AIDP are prolonged Fwave latencies or poor F-wave repeatability due to demyelination of the nerve roots. This is followed by prolonged distal latencies (due to distal demyelination) and temporal dispersion or conduction block. Slowing of nerve conduction velocities is less helpful as it tends to appear two to three weeks after the onset. However, the sensitivity of nerve conduction studies (NCS) based on reported criteria may be as low as $22 \%$ in early AIDP, rising to $87 \%$ at five weeks into the illness $[46,47]$.

\subsubsection{Lumbar Puncture}

A lumbar puncture is often performed in patients with suspected GBS. Importantly, this procedure especially should be done to exclude other diagnoses rather than to confirm GBS. A combination of elevated protein level and normal cell counts in the CSF (termed albumin cytological dissociation) is considered a hallmark of GBS (48). A frequent misconception, however, is that albumin cytological dissociation must always be present to confirm the diagnosis, as only $64 \%$ of patients with GBS have this feature [48]. Elevated CSF protein levels are found in approximately $50 \%$ of patients in the first 3 days after onset of weakness, which increases to $80 \%$ after the first week [49]. CSF cell counts $>50$ cells per $\mu 1$ should cast doubt on the diagnosis of GBS, and other differential diagnoses should be considered, such as leptomeningeal malignancy, lymphoma, cytomegalovirus radiculitis, HIV polyneuropathy and poliomyelitis $[48,50]$. In the Miller Fisher syndrome, the proportion of patients with raised CSF protein has been reported to range from $25 \%$ in the first week to $84 \%$ in the third week [50].

\subsubsection{Serum Antiganglioside Antibodies}

Although antiganglioside antibodies are involved in the pathogenesis of GBS, their role in diagnosis has not been established. In general, the frequency of each specific antibody is low, implying that the negative predictive value of detection tests will also be low, and that the negative test 
findings cannot, therefore, exclude GBS as a diagnosis [50, 51]. Possible exceptions to this rule might be anti-GQ1b antibodies, which are present in the serum of at least $90 \%$ of patients with MFS [51], and anti-GM1 and anti-GD1a IgG antibodies, which are frequently found in patients with AMAN [52].

\subsubsection{Brain and Spinal Magnetic Resonance Patterns}

Typical findings in Guillain-Barré syndrome are surface thickening and contrast enhancement on the conus medullaris and the nerve roots of the cauda equine. The most common site of enhancement in Guillain-Barré syndrome is considered to be anterior nerve roots, although enhancement of the posterior nerve roots is also seen $[53,54]$.

\subsection{Therapy}

\subsubsection{Intravenous Immunoglobulins (IVig)}

The postulated mechanisms of action of IVIg in neuromuscular disorders include interference with costimulatory molecules involved in antigen presentation and modulation of autoantibodies, cyotokines and adhesion molecules production as well as macrophage Fc receptor. It also disrupst complement activation and membrane attack complex formation $[45,55]$. Sialylated $\operatorname{IgG}$ Fc fragments are important for the in vivo activity of intravenous immunoglobulin since they initiate an anti-inflammatory cascade through the lectin receptor SIGN-R1 or DC-SIGN [45, 55]. This leads to upregulated surface expression of the inhibitory $\mathrm{Fc}$ receptor, Fc gamma receptor IIb, on inflammatory cells, thereby attenuating autoantibody-initiated inflammation [45, 55]. According to the standard treatment regimen, immune globulin is given at a total dose of $2 \mathrm{~g}$ per kilogram of body weight over a period of 5 days [55].

\subsubsection{Plasma Exchange}

Plasma exchange was the first treatment that was found to be effective in hastening recovery in patients with the Guillain-Barré syndrome and it appeared to be most effective when it was started within the first 2 weeks after disease onset in patients who were unable to walk [56]. An electrophysiological examination is not always required for the initiation of immunotherapy. Plasma exchange nonspecifically removes antibodies and complement and appears to be associated with reduced nerve damage and faster clinical improvement, as compared with supportive therapy alone [57]. The usual empirical regimen is five exchanges over a period of 2 weeks, with a total exchange of 5 plasma volumes $[56,57]$.

\subsection{Aan Practice Parameters}

They recommend PE for nonambulant adult patients with GBS who seek treatment within four weeks of the onset of symptoms (level A). PE should also be considered for ambulant patients examined within two weeks of the onset of symptoms (level B). IVIg is recommended for nonambulant adult patients with GBS within two (level A) or possibly four weeks (level B) of the onset of neuropathic symptoms. It also indicates that sequential treatment with PE followed by IVIg, or immunoabsorption followed by IVIg is not recommended for patients with GBS. As stated earlier, corticosteroids are not recommended for the management of GBS. In children with severe GBS, PE and IVIg are treatment options [57].

\subsection{Rhabdomyolisis and Guillain Barre'}

Rhabdomyolysis is a complex medical condition involving the rapid dissolution of damaged or injured skeletal muscle. This disruption of skeletal muscle integrity leads to the direct release of intracellular muscle components, including myoglobin, creatine kinase (CK), aldolase, and lactate dehydrogenase, as well as electrolytes, into the bloodstream and extracellular space. Rhabdomyolysis ranges from an asymptomatic illness with elevation in the CK level to a lifethreatening condition associated with extreme elevations in $\mathrm{CK}$, electrolyte imbalances, acute renal failure (ARF), and disseminated intravascular coagulation [58].

We performed a literature review considering the terms "Hyperckemia and Guilain-Barrè", "Creatinkinase and Guillain-Barrè", "Creatinkinase and AIDP", "Hyperckemia and AIDP", "Rhabdomyolisis and Guillain-Barrè". "Rhabdomyolisis and AIDP", "Hyperckemia and facial diplegia", "Creatinkinase and facial diplegia", "Rhabdomyolisis and facial diplegia".

Table 1. Describes case reports in literature with rhabdomyolisis and Guillain Barrè Syndrome ABBREVIATIONS: F= female, M= male, U=unknown data.

\begin{tabular}{|c|c|c|c|c|c|}
\hline Author & Age & Sex & Neurological symptoms & Creatinkinase & General symptoms \\
\hline Hargis M 2017 & 45 & M & $\begin{array}{l}\text { Progressive weakness of the lower extremities. Facial and } \\
\text { left, more than right, proximal upper extremity weakness. }\end{array}$ & $\mathrm{U}$ & none \\
\hline $\begin{array}{l}\text { Van Den Berg } \\
M \text { et al } 2016\end{array}$ & 60 & $\mathrm{~F}$ & $\begin{array}{l}\text { muscle weakness, sensory disturbances, hyporeflexia in her } \\
\text { limbs and facial diplegia }\end{array}$ & raised & $\begin{array}{l}\text { diarrhoea, fever and an } \\
\text { unsteady gait after returning } \\
\text { from Surinam. }\end{array}$ \\
\hline $\begin{array}{l}\text { Sanena A et al } \\
2014\end{array}$ & 24 & $\mathrm{~F}$ & $\begin{array}{l}20 \text { days history of weakness of both lower and upper } \\
\text { extremities }\end{array}$ & $7002 \mathrm{UI} / \mathrm{L}$ & none \\
\hline $\begin{array}{l}\text { Gupta R et al } \\
2016\end{array}$ & 25 & $\mathrm{~F}$ & $\begin{array}{l}\text { acute respiratory distress syndrome (ARDS), difficulty in } \\
\text { moving all four limbs }\end{array}$ & $11510 \mathrm{IU} / \mathrm{L}$ & $\begin{array}{l}\text { high-grade fever, anorexia, } \\
\text { malaise, dry cough and } \\
\text { breathlessness }\end{array}$ \\
\hline $\begin{array}{l}\text { Scott AJ et al } \\
2000\end{array}$ & 25 & M & $\begin{array}{l}\text { weakness of his hands and legs which progressed over } \\
\text { several hours until he was unable to walk. }\end{array}$ & $10,150 \mathrm{IU} / \mathrm{I}$ & $\begin{array}{l}\text { anterior chest pain radiating to } \\
\text { the inner aspect of both arms }\end{array}$ \\
\hline $\begin{array}{l}\text { Satoh Jet al } \\
1999\end{array}$ & 21 & M & $\begin{array}{l}\text { Progressive weakness after an episode of diarrhea, } \\
\text { worsening to rapid quadriplegia and areflexia }\end{array}$ & $\begin{array}{l}\text { 1917UI/L (raised } \\
\text { two weeks after } \\
\text { plasmapheresis) }\end{array}$ & diarrhea \\
\hline
\end{tabular}


Table 1. Continue.

\begin{tabular}{|c|c|c|c|c|}
\hline Author & Electroneurography & Csf & Aetiology & Treatment \\
\hline $\begin{array}{l}\text { Hargis } M \\
2017\end{array}$ & $\begin{array}{l}\text { slowed conduction velocities without conduction block, and absent } \\
\text { F-waves consistent with acute inflammatory demyelinating } \\
\text { polyradiculoneuropathy }\end{array}$ & $\mathrm{U}$ & $\mathrm{U}$ & Plasmapheresis \\
\hline $\begin{array}{l}\text { Van Den Berg } \\
\text { M et al } 2016\end{array}$ & Confirmed GCS & $\begin{array}{l}\text { Albumin-cytological } \\
\text { dissociation }\end{array}$ & Zika virus & $\begin{array}{l}\text { Intravenous } \\
\text { immunoglobulins }\end{array}$ \\
\hline $\begin{array}{l}\text { Sanena A et } \\
\text { al } 2014\end{array}$ & acute motor and sensory axonal neuropathy & $\begin{array}{l}\text { protein of } 68 \mathrm{mg} / \mathrm{dL} \text {, } \\
\text { glucose of } 90 \mathrm{mg} / \mathrm{dL} \\
\text { and a CSF cell count } \\
\text { of } 2 \text { leukocytes } / \mathrm{mm}\end{array}$ & U & $\mathrm{U}$ \\
\hline $\begin{array}{l}\text { Gupta R et al } \\
2016\end{array}$ & $\begin{array}{l}\text { reduced amplitude of compound motor action potential in all the } \\
\text { nerves tested with relative preservation of the nerve conduction } \\
\text { velocities, F waves not recordable. Sensory nerve conduction: } \\
\text { reduced amplitude of the sensory nerve action potentials with relative } \\
\text { preservation of the nerve conduction velocities. Electromyogram } \\
\text { (EMG): fibrillation potentials and positive sharp waves }\end{array}$ & 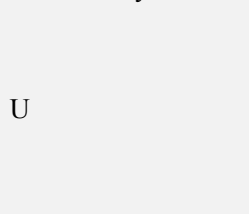 & $\begin{array}{l}\text { Anti-mycoplasma } \\
\text { IgG antibodies were } \\
\text { persistently elevated } \\
84 \mathrm{U} / \mathrm{ml} \text { after one } \\
\text { month }(>30 \mathrm{U} / \mathrm{ml} \\
\text { positive) }\end{array}$ & U \\
\hline $\begin{array}{l}\text { Scott AJ et al } \\
2000\end{array}$ & $\begin{array}{l}\text { severe demyelinating neuropathy affecting both proximal and } \\
\text { distal segments of motor and sensory nerves in all four limbs. }\end{array}$ & $\begin{array}{l}\text { Protein } 0.28 \mathrm{~g} / 1 \text {. No } \\
\text { cells }\end{array}$ & ( & plasmapheresis \\
\hline $\begin{array}{l}\text { Satoh J et al } \\
1999\end{array}$ & severe axonal degeneration of motor nerve terminals & $\begin{array}{l}\text { Protein } 235 \mathrm{mg} / \mathrm{dl} \\
\text { without pleocytosis }\end{array}$ & $\begin{array}{l}\text { Campylobacter } \\
\text { jejuni enteritis }\end{array}$ & plasmapheresis \\
\hline
\end{tabular}

\section{Discussion}

Our patient was in-hospitalized to rhabdomyolisis quickly followed by acute facial diplegia with dysphagia, hypophonia and dyspnea quickly worsening. Due to brain computer tomography and magnetic resonance imaging of Arnold Chiari malformation, we decided not to perform lumbar puncture but to move the patient to ICU, where we promptly administered IVig on the basis of the electroneurography results (myopathic pattern was excluded by electromyography). Considering the quick improvement of bulbar symptoms diagnosis of AIDP was confirmed. We couldn't find infective source (laboratory tests for Zika Virus, an arthropod-borne virus (arbovirus) in the genus Flavivirus and the family Flaviviridae which had been isolated also in Cambodia at the beginning of 2016, couldn't be available).

Modestly raised levels of CK (up to seven times the upper limit of normal) have been documented in the early stages of GBS, correlating with the occurrence of pain [59], which was a presenting symptom in our patient. The cause of raised levels of CK in early GBS is uncertain. Muscle denervation can result in release of muscle enzymes. The muscle pathology in this patient was typical of acute rhabdomyolysis, which was not found in muscle biopsies from patients with GBS in Ropper's series [59]. Negative history of trauma, illicit drug or alcohol abuse, toxin consumption or recurrent episodes of rhabdomyolysis in the past ruled out the other possible causes of rhabdomyolysis [59].

\section{Conclusion}

In literature we haven't found cases of rhabdomyolisis associated to facial dyplegia. In such cases is important to promptly diagnose and treat AIDP without forgetting to monitor renal function and creatin kinase value.

\section{Conflicts of Interest}

All the authors denies any conflict of interest.

\section{References}

[1] Harms M Inpatient management of guillain-barré syndrome. Neurohospitalist. 2011 Apr; 1 (2): 78-84.

[2] Hayden RDM, Cornblath DR, Hughes RAC, et al. Electrophysiological classification of Guillain-Barré Syndrome: clinical associations and outcomes. Ann Neurol. 1998; 44 (5): 780-788.

[3] Landry JB. Note sur la paralysie ascendante aigue. Gaz Hebd Med Chir. 1859; 6: 472-474, 486-488.

[4] Osler W. The principles and practice of medicine: designed for the use of practitioners and students of medicine. New York: Appleton; 1892.

[5] Guillain G, Barré J, Strohl A. Sur un syndrome de radiculonévrite avec hyperalbuminose du liquide céphalorachidien sans réaction cellulaire. Remarques sur les caractères cliniques et graphiques des réflexes tendineux. Bull Mem Soc Med Hop Paris. 1916; 40: 1462-70.

[6] Haymaker WE, Kernohan JW The Landry-Guillain-Barré syndrome; a clinicopathologic report of 50 fatal cases and a critique of the literature. Medicine (Baltimore). 1949 Feb; 28 (1): 59-141.

[7] Asbury AK, Arnason BG, Adams RD The inflammatory lesion in idiopathic polyneuritis. Its role in pathogenesis. Medicine (Baltimore). 1969 May; 48 (3): 173-215.

[8] McGrogan A, Madle GC, Seaman HE, de Vries CS. The epidemiology of Guillain-Barré syndrome worldwide: A systematic literature review. Neuroepidemiology. 2009; 32 (2): $150-163$.

[9] Rees JH, Thompson RD, Smeeton NC, Hughes RAC. Epidemiological study of Guillain-Barré syndrome in south east England. J Neurol Neurosurg Pscyh. 1998; 64 (1): 74-77. 
[10] Guillain-Barré Study Group Guillain-Barré syndrome: an Italian multicentre case-control study. Neurol Sci. 2000; 21 (4): 229-234.

[11] Alshekhlee A, Hussain Z, Sultan B, Katirji B. Guillain Barre syndrome: incidence and mortality rates in US hospitals. Neurology. 2008; 70 (18): 1608-1613.

[12] Bersano A, Carpo M, Allaria S, Franciotta D, Citterio A, Nobile-Orazio E. Long term disability and social status change after Guillain-Barré syndrome. J Neurol. 2006; 253 (2): 214-218.

[13] Londono XA, Lewis RA Gullain-Barrè Syndrome Semin Neurol 2012; 32: 179-186.

[14] Hadden RDM, Karch H, Hartung H-P, et al; Plasma Exchange/Sandoglobulin Guillain-Barré Syndrome Trial Group. Preceding infections, immune factors, and outcome in Guillain-Barré syndrome. Neurology 2001; 56 (6): 758-765.

[15] Van Koningsveld R, Rico R, Gerstenbluth I, et al. Gastroenteritis associated Guillain-Barré syndrome on the Caribbean island Curaçao. Neurology 2001; 56 (11): 14671472.

[16] Schonberger LB, Bregman DJ, Sullivan-Bolyai JZ, Keenlyside RA, Ziegler DW, Retailliau HF, et al. GuillainBarre syndrome following vaccination in the National Influenza Immunization Program, United States, 1976-1977. Am J Epidemiol. 1979; 110 (2): 105-23.

[17] Centers for Disease C, Prevention. Preliminary results: surveillance for Guillain-Barre syndrome after receipt of influenza A (H1N1) 2009 monovalent vaccine - United States, 2009-2010. MMWR Morb Mortal Wkly Rep. 2010; 59 (21): 657-61.

[18] Salmon DA, Proschan M, Forshee R, Gargiullo P, Bleser W, Burwen DR, et al. Association between Guillain-Barre syndrome and influenza A (H1N1) 2009 monovalent inactivated vaccines in the USA: a meta-analysis. Lancet. 2013; 381 (9876) 1461-8.

[19] Sanz Fadrique R, Martín Arias L, Molina-Guarneros JA1, Jimeno Bulnes N, García Ortega P. Guillain-Barré syndrome and influenza vaccines: current evidence. Rev Esp Quimioter. 2019 Aug; 32 (4): 288-295. Epub 2019 Jun 20.

[20] Fujimura $\mathrm{H}$ The Guillain-Barrè Syndrome Chapter 21. Handbook of Clinical Neurology, Vol. 115 (3rd series) Peripheral Nerve Disorders G. Said and C. Krarup, Editors (C) 2013 Elsevier B. V.

[21] Bourque PR, Chardon JW, Massie R Autoimmune peripheral neuropathies. Clin Chim Acta. 2015 Sep 20; 449: 37-42.

[22] Hiraga A, Mori M, Ogawara K, Kojima S, KanesakaT, Misawa T, Hattori T, Kuwabara S Recovery patterns and long term prognosis for axonal Guillain-Barré syndrome 2005 May; 76 (5): 719-722.

[23] Kimoto K, Koga M, Odaka M, Hirata K, Takahashi M, Li J, Gilbert M, Yuki N. Relationship of bacterial strains to clinical syndromes of Campylobacter-associated neuropathies. Neurology. 2006 Nov 28; 67 (10): 1837-43.

[24] Yuki N, Ho TW, Tagawa Y, et al. Autoantibodies to GM1b and GalNAc-GDla: relationship to Campylobacter jejuni infection and acute motor axonal neuropathy in China. J Neurol Sci 1999; 164: 134-8.
[25] Ang CW, Jacobs BC, Laman JD. The Guillain-Barré syndrome: a true case of molecular mimicry. Trends Immunol 2004; 25: 61-6.

[26] Chiba A, Kusunoki S, Obata H, Machinami R, Kanazawa I. Serum anti-GQ1b IgG antibody is associated with ophthalmoplegia in Miller Fisher syndrome and GuillainBarré syndrome: clinical and immunohistochemical studies. Neurology 1993; 43: 1911-7.

[27] Chiba A, Kusunoki S, Shimizu T, Kanazawa I. Serum IgG antibody to ganglioside GQ1b is a possible marker of Miller Fisher syndrome. Ann Neurol 1992; 31: 677-9.

[28] Nishimoto Y, Odaka M, Hirata K, Yuki N. Usefulness of antiGQ1b IgG antibody testing in Fisher syndrome compared with cerebrospinal fluid examination. J Neuroimmunol 2004; 148: $200-5$.

[29] Liu JX, Willison HJ, Pedrosa-Domellof F. Immunolocalization of GQ1b and related gangliosides in human extraocular neuromuscular junctions and muscle spindles. Invest Ophthalmol Vis Sci 2009; 50: 3226-32.

[30] Wakerley BR, Uncini A, Yuki N, and the GBS Classification Group. Guillain-Barré and Miller Fisher syndromes - new diagnostic classification. Nat Rev Neurol 2014; 10: 537-44.

[31] Wakerley BR, Yuki N. Pharyngeal-cervical-brachial variant of Guillain-Barre syndrome J Neurol Neurosurg Psychiatry. 2014 Mar; 85 (3): 339-44.

[32] Nagashima T, Koga M, Odaka M, Hirata K, Yuki N. Continuous spectrum of pharyngeal-cervical-brachial variant of Guillain- Barré syndrome. Arch Neurol 2007; 64 (10): $1519-1523$.

[33] Kashihara K, Shiro Y, Koga M, Yuki N. IgG anti-GT1a antibodies which do not cross react with GQ1b ganglioside in a pharyngealcervical- brachial variant of Guillain-Barré syndrome. J Neurol Neurosurg Psychiatry 1998; 65 (5): 799.

[34] Lee SS, Lee SH. Does sensory Guillain-Barré syndrome exist without any abnormalities in motor nerve conduction? Neurology. 2006; 66: 947-948.

[35] Yang J, Huan M, Jiang H, Song C, Zhong L, Liang Z Pure sensory Guillain-Barré syndrome: A case report and review of the literature Exp Ther Med. 2014 Nov; 8 (5): 1397-1401.

[36] Wakerley BR, Yuki N. Isolated facial diplegia in GuillainBarré syndrome: Bifacial weakness with paresthesias. Muscle Nerve. 2015; 52 (6): 927-32.

[37] Susuki K, Koga M, Hirata K, Isogai E, Yuki N. A GuillainBarré syndrome variant with prominent facial diplegia. J Neurol. 2009; 256 (11): 1899-905.

[38] Dal Verme A, Acosta P, Margan M, Pagnini C, Dellepiane E, Peralta C. Facial diplegia with atypical paresthesia. A variant of Guillain-Barré syndrome. Medicina. 2015; 75 (3): 178-80.

[39] Akarsu EO, Yalcın D, Surmeli R, Demir A, Sunter G, Diler Y. A rare variant of guillain-barre syndrome: facial diplegia paresthesia. Turk J Neurol. 2015; 21: 171-74.

[40] Koike H, Atsuta N, Adachi H, et al. Clinicopathological features of acute autonomic and sensory neuropathy. Brain 2010; 133 (10): 2881-2896.

[41] Esposito S, Longo MR. Guillain-Barré syndrome. Autoimmun Rev. 2017 Jan; 16 (1): 96-101. 
[42] Soliven B. Animal models of autoimmune neuropathy. ILAR J 2014; 54: 282-90.

[43] Sudo M, Miyaji K, Späth PJ, Morita-Matsumoto K, Yamaguchi Y, Yuki N. Polyclonal IgM and IgA block in vitro complement deposition mediated by anti-ganglioside antibodies in autoimmune neuropathies. Int Immunopharmacol 2016; 40: 11-5.

[44] Kuwabara S. Guillain-Barré syndrome. Epidemiology, pathophysiology andmanagement. Drugs 2004; 64: 597-610.

[45] Dimachkie MM, Barohn RJ Guillain-Barré Syndrome and Variants Neurol Clin. 2013 May; 31 (2): 491-510.

[46] Asbury AK, Cornblath DR. Assessment of current diagnostic criteria for Guillain-Barré syndrome. Ann Neurol. 1990; 27 (Suppl): S21-S24.

[47] Albers JW, Donofrio PD, McGonagle TK. Sequential electrodiagnostic abnormalities in acute inflammatory demyelinating polyradiculoneuropathy. Muscle Nerve. 1985; 8 (6): 528-539.

[48] Van den Berg B, Walgaard C, Drenthen J, Fokke C, Jacobs BC, van Doorn PA. Guillain-Barré syndrome: pathogenesis, diagnosis, treatment and prognosis. Nat Rev Neurol. 2014 Aug; 10 (8): 469-82.

[49] Fokke, C. et al. Diagnosis of Guillain-Barré syndrome and validation of Brighton criteria. Brain 2014; 137, 33-43.

[50] Nishimoto Y, Odaka M, Hirata K. Usefulness of anti-GQ1b IgG antibody testing in Fisher syndrome compared with cerebrospinal fluid examination. J Neuroimmunol 2014; 148: 200-205.
[51] Mori, M. \& Kuwabara, S. Fisher syndrome. Curr. Treat. Options Neurol 2011; 13: 71-78.

[52] Kuwabara, S. \& Yuki, N. Axonal Guillain-Barré syndrome: concepts and controversies. Lancet Neurol. 2013; 12: 11801188 .

[53] Fulbright RK, Erdum E, Sze $G$ et-al. Cranial nerve enhancement in the Guillain-Barré syndrome. AJNR Am J Neuroradiol. 1995; 16 (4): 923-5.

[54] Alkan O, Yildirim T, Tokmak N et-al. Spinal MRI findings of guillain-barré syndrome. J Radiol Case Rep. 2009; 3 (3): 25-8.

[55] Plasma Exchange/Sandoglobulin Guillain- Barré Syndrome Trial Group. Randomised trial of plasma exchange, intravenous immunoglobulin, and combined treatments in Guillain-Barré syndrome. Lancet 1997; 349: 225-30.

[56] The French Cooperative Group on Plasma Exchange in GuillainBarré Syndrome. Appropriate number of plasma exchanges in Guillain-Barré syndrome. Ann Neurol 1997; 41: 298-306.

[57] Hughes RA, Wijdicks EF, Barohn R, Benson E, Cornblath DR, Hahn AF, Meythaler JM, Miller RG, Sladky JT, Stevens JC. Quality Standards Subcommittee of the American Academy of Neurology. Practice parameter: immunotherapy for Guillain-Barré syndrome: report of the Quality Standards Subcommittee of the American Academy of Neurology. Neurology. 2003 Sep 23; 61 (6): 736-740.

[58] Torres PA, Helmstetter JA, Kaye AM, Kaye AD Rhabdomyolysis: pathogenesis, diagnosis, and treatment. Ochsner J. 2015 Spring; 15 (1): 58-69.

[59] Ropper, A. H. \& Shahani, B. T. Pain in Guillain-Barre syndrome. Arch Neurol 1984, 41: 511-514. 